\title{
MAQUIAVELO Y LA PERFIDIA DE VENECIA
}

\section{MACHIAVELLI AND THE PERFIDY OF VENICE}

\section{Roberto García Jurado}

Universidad Autónoma Metropolitana. México.

rgarcia@correo.xoc.uam.mx

Recibido: septiembre de 2018

Aceptado: noviembre de 2018

Palabras clave: Venecia, república, aristocracia, democracia, dogo.

Keywords: Venice, aristocracy, republic, democracy, doge.

Resumen: Maquiavelo no sentía simpatía ni agrado por Venecia. A pesar de que sólo Venecia y Florencia, su patria, eran los dos grandes estados italianos que a principios del siglo XVI habían conservado gobiernos republicanos, lo que hipotéticamente debía hermanarlas, entre ambas repúblicas había más competencia que cooperación, lo cual se reflejaba fielmente en el pensamiento y opiniones de Maquiavelo. Además, Venecia constituía un modelo de república aristocrática que contrastaba con el modelo de república democrática de la antigua Roma que tanto admiraba Maquiavelo, lo cual acentuaba su desagrado. Más aún, el gobierno republicano de Florencia de 1494-1512 al que sirvió Maquiavelo, trató de reformarse a imagen y semejanza de las instituciones políticas venecianas, en lo cual no tuvo mucho éxito. De este modo, el ejemplo de Venecia suscitó una serie de reflexiones y opiniones de Maquiavelo sobre el gobierno republicano que son dignas de análisis y que constituyen la materia de este escrito.

Abstract: Machiavelli felt no sympathy or liking for Venice. Although only Venice and Florence, their homeland, were the two great Italian states that had retained republican governments at the beginning of the 16th century, which hypothetically had to be twinned, between both republics there was more competition than cooperation, which was faithfully reflected in the thought and opinions of Machiavelli. In addition, Venice was a model of an aristocratic republic that contrasted with the model of democratic republic of ancient Rome that so pleased Machiavelli, which accentuated his displeasure. Moreover, the republican government of Florence of 14941512 that Machiavelli served, tried to reform itself in the image and likeness of Venetian political institutions, in which he was not very successful. In this way, the example of Venice aroused a series of reflections and opinions of Machiavelli on republican government that are worthy of analysis and that constitute the subject of this writing. 


\section{Introducción}

Maquiavelo sentía un profundo desagrado y desprecio por Venecia y los venecianos. Lo expresó así en varias ocasiones, y aunque en otras tantas declaró su admiración por ciertas cualidades de este Estado, el balance general no puede sino conducir a esa impresión. A primera vista, esta opinión puede parecer sorprendente y desconcertante, ya que en los tiempos de Maquiavelo, Venecia y Florencia eran los únicos dos grandes Estados italianos que habían conservado las instituciones republicanas adoptadas en la época comunal, por lo tanto, podría decirse que eran repúblicas hermanas. Un vínculo que debía ser muy fuerte si se toma en cuenta que durante una buena parte del siglo XV las dos repúblicas se unieron para contener el ímpetu expansionista del ducado de Milán, un gobierno señorial y tiránico, como muchos otros que habían sojuzgado a casi todas las ciudades italianas desde el siglo XIV.

En este sentido, cuando Maquiavelo hace un recuento de los Estados italianos más fuertes de su época en el Capítulo XI de El príncipe, toma en cuenta a cinco: los Estados pontificios; el reino de Nápoles; el ducado de Milán; la república de Venecia; y la república de Florencia, es decir, tres principados y dos repúblicas. De estos cinco, las repúblicas no sólo eran minoría, sino que muchos otros grandes Estados italianos que en los siglos precedentes habían tenido también instituciones republicanas, como Génova, Pisa, Verona, Brescia o Bolonia, se habían convertido en principados para el siglo XVI, dejando sólo a Venecia y Florencia como las únicas muestras significativas del pasado comunal y republicano de la Italia tardomedieval.
Maquiavelo no era el único en Florencia ni en Italia que tenía esa mala opinión de los venecianos. Ya mucho antes, Giovanni Villani, el gran cronista de Florencia, había considerado a los venecianos una como raza pérfida. También Francisco Guicciardini, otro de los pesadores políticos florentinos más ilustres del periodo, tenía una impresión muy similar, al cual se sumaban muchos otros personajes ilustres de la época, como el propio papa Julio II, quien fue a fin de cuentas el verdugo del Imperio veneciano en 1509.

Pero también había en el resto de Italia y en la propia Florencia sinceros admiradores de Venecia. Luego de la expulsión de los Medici en 1494, Florencia inició todo un proceso de refundación política inspirada por el fraile Girolamo Savonarola, quien trató de imitar los rasgos constitucionales básicos de Venecia, comenzando por el Consejo Mayor, el cual fue la instancia política fundamental sobre la que se basó la ciudad en los años que duró ese gobierno republicano. Incluso en 1502, cuatro años después de haber desaparecido Savonarola, los ottimati de la ciudad propusieron y lograron que se creara en Florencia una magistratura como el dogo de Venecia, que por su carácter vitalicio consideraban que le daría a su Estado la estabilidad que tanto buscaban.

No obstante, a pesar de sus instituciones políticas, de su mítica longevidad y de su defensa de las libertades italianas, Venecia despertaba muy pocas simpatías en Maquiavelo, aunque en partes cruciales de su pensamiento político se valoraran significativamente todas esas cualidades. En este sentido, el objetivo de este escrito es precisamente exponer las opiniones de Maquiavelo sobre la Serenissima y explicar las razones de su animadversión, con el fin de contribuir así a una mejor 
comprensión y explicación de sus ideas republicanas y nacionalistas.

\section{Historia y mito}

Cuando Maquiavelo habla de Venecia en su Historia de Florencia, escrita en los años veinte del siglo XVI, comienza por reconocer que en ese momento es el Estado más importante de Italia, tanto por su organización como por su poderío. Y tenía razón, porque de todos los Estados italianos, Venecia era la que había conservado el mayor margen de independencia y autonomía frente al exterior desde que comenzaron las guerras italianas de 1494 (Maquiavelo, 2009: 64; Cronin, 1972: 176-193).

Aproximadamente en los diez años que habían transcurrido desde 1513, cuando en el Capítulo XI de El príncipe Maquiavelo hacía el recuento de los cinco Estados italianos más importantes, casi todos ellos habían terminado de perder su autonomía: Nápoles había caído irremediablemente bajo el dominio español, Milán bajo el francés, Florencia se había convertido en un satélite de los Estados pontificios, y finalmente éstos, de la mano del papa, habían seguido una política errática de aproximación y disociación frente a Francia y España, que terminaría tristemente con el sometimiento a esta última, simbolizado con la coronación de Carlos V como emperador por parte de Clemente VII en 1530. Solo Venecia, con enormes dificultades, había conservado su autonomía (Maquiavelo, 2010: 92-93; Hay y Law, 1989: 149-168).

En este mismo pasaje, Maquiavelo plantea que este resultado se debía en buena medida al desarrollo histórico de ese Estado, y para ilustrarlo se remonta hasta la época de su fundación.
Maquiavelo ya se había referido a la fundación de Venecia en los Discursos poniéndola como ejemplo de tres cosas. En primer lugar, la pone como ejemplo de las repúblicas que no son fundadas por extranjeros, sino que las crean los hombres que radicaban con anterioridad ahí y que por alguna razón decidieron en un cierto momento congregarse para fundar un Estado. En segundo lugar, la exhibe como una de las repúblicas cuya creación y legislación fundacional no se debe a un gran líder, sino que es producto del genio y empeño del conjunto de los individuos que forman la república. En tercer lugar, denota el acierto de sus fundadores al elegir un lugar apropiado para su defensa, como era el caso de Venecia, que no era accesible por tierra para sus enemigos, solo por mar (Maquiavelo, 2005: 47-51; Guicciardini, 2006: 51).

Maquiavelo recomienda en ese mismo pasaje establecerse en lugares fértiles y productivos, de donde podría inferirse una crítica a los primeros venecianos que eligieron este lugar pantanoso e insalubre. No obstante, en este mismo pasaje reconoce que cuando hay restricciones importantes a la libertad de elección, tal y como la experimentaron éstos, la virtud de los fundadores de estas repúblicas es mayor, lo que constituye indirectamente y en conjunto un reconocimiento a virtud de los fundadores de Venecia (Maquiavelo, 2005: 30; Diehl, 1961: 15-18; Psarra, 2018: 27-81).

Como se ha dicho ya, en el Capítulo XXIX del Libro I de la Historia de Florencia Maquiavelo hace un recuento de las primeras fases de la historia de Venecia. Tal vez sea pertinente señalar que Maquiavelo dedica casi la totalidad de este Libro I a exponer la historia de Roma y el papado, incluyendo también breves pasajes o ca- 
pítulos dedicados tanto a Venecia como a Milán, pero dejando hasta el Libro II el inicio propiamente de la historia de Florencia (Maquiavelo, 2009: 29-75).

En este sentido, Maquiavelo recoge en el Capítulo XXIX una parte de la historia legendaria de Venecia, una versión que los mismos venecianos se complacían en difundir, la cual contaba que los primeros habitantes de las islas habían llegado a ellas huyendo de la invasión de los bárbaros, particularmente de la furia de los hunos, quienes conducidos por Atila habían atacado Aquilea y los territorios circunvecinos en 452, por lo que sus habitantes se habían refugiado en esta zona, tanto por el miedo a los bárbaros como por su resistencia a la sumisión, conservando así su libertad, que con el paso del tiempo convertirían en principio y dogma constitucional de su vida política (Norwich, 1989: 3-14; Ravegnani, 2006: 11-33; y Lane, 1978: 3-15).

Ciertamente, es muy probable que el mayor impulso poblacional en su origen sea precisamente la invasión de Atila, sin embargo, la región ya se había comenzado a poblar mucho antes, al grado de que el mismo emperador Augusto había dividido Italia en diez provincias, siendo una de ellas precisamente Venetia e Istria, razón por la cual, dice Maquiavelo, desde la misma antigüedad esa provincia ya se llamaba Venecia. No obstante, es muy probable que la primera oleada poblacional de importancia se diera a raíz de la invasión de los visigodos comandados por Alarico en el 401, dado que algunos años después se dio un acontecimiento que es considerado la ceremonia de fundación de la ciudad, cuando el 25 de marzo del 421, día de la Anunciación, se fundó la iglesia de San Giacometo (Baron, 1955: 203; Burkhardt, 1984: 35).
A partir de esa época, los pobladores de la zona se fueron acercando y concentrando en uno de los montículos más altos de las islas, en el Rivus Altus, de donde se derivó el nombre de Rialto, a donde dice Maquiavelo que Ilegaron principalmente los paduanos que también huían de Atila, por lo que desde entonces se convirtió en el centro urbano de la ciudad (Diehl, 1961: 17-18; Psarra, 2018: 83-137).

Estos años de fundación y poblamiento pueden ser considerados la primera etapa de la historia de Venecia, que bien puede dividirse en cinco segmentos si se parte desde su origen hasta la época del Renacimiento.

Partiendo de ese supuesto, la segunda etapa de esta historia se abre a fines del siglo VI, con la ofensiva de Bizancio sobre los godos, quienes controlaban todo el norte de la península, gracias a la cual consiguió someter toda esta zona a su dominio imperial, incluida la propia Venecia (Ravegnani, 2006: 20-46).

De este modo, inicia todo un período de sometimiento a Bizancio que no acabaría sino hasta fines del siglo VIII. Durante estos dos siglos Venecia fue gobernada mediante la estructura administrativa del Imperio, el cual desde fines del siglo VI había creado un exarca radicado en Ravena, el cual gobernaba todo el territorio nororiental de la península a través de una red de duques nombrados por el propio emperador.

En esta época vuelven a destacarse los rasgos de libertad y autonomía que los venecianos se sentían orgullosos de exaltar. Como lo dice Maquiavelo, desde los tiempos de los primeros asentamientos sus habitantes se gobernaron con sus propias leyes y orchini, una especie de tribunos elegidos popularmente, a los cuales vino 
a sobreponerse el duque designado por el exarca de Ravena, el dogo, como lo traducían los venecianos. Sin embargo, a fines del siglo VII se suscitó una rebelión en contra del exarcado, a partir de la cual lograron que el duque que los gobernaba fuera elegido popularmente (Maquiavelo, 2009: 65; Norwich, 1989: 15-25).

Del mismo modo, desde esta época los venecianos pusieron distancia y límites frente a la autoridad eclesiástica de Roma. Aprovechando su dependencia política de Bizancio y las distancias que se fueron incrementando entre la iglesia romana y la bizantina, se resistieron y marginaron cada vez más de la jerarquía católica.

A mediados del siglo VI se suscitó un conflicto dogmático religioso acerca de la naturaleza humana y/o divina de Cristo, un conflicto que alcanzó tales proporciones que un conjunto de obispos de la zona nororiental de la península se alejó y desvinculó de Roma, protagonizando el llamado Cisma de los Tres Capítulos. Desde entonces, las relaciones entre el papado y la iglesia local no fueron las mejores, al grado de que a mediados del siglo IX lograron arrancarle a Roma la facultad de nombrar a sus propios obispos y de retener los diezmos y las contribuciones ordinarias del clero.

Tanta importancia alcanzó la iglesia local veneciana, que se fundó un consejo llamado los Procuradores de San Marcos, formado por nueve patricios destacados de la ciudad, cuya relevancia se deduce directamente al considerar que casi todos los dogos ocuparon primero el cargo de procurador (Gilbert, 1980: 10).

La tercera etapa del desarrollo histórico de Venecia la marca la caída de Ravena a manos de los longobardos en el 751. Su invasión del norte de la península provocó un serio debilitamiento del control que ejercía Bizancio en la zona, al grado de que nunca pudo recuperarlo del todo. Dado que Bizancio se encontraba muy presionada por su lucha contra los turcos y le era imposible recuperar el norte de Italia y simultáneamente ayudar a Roma ante el asedio de éstos, el papa Esteban II no vio otro recurso que pedir ayuda a Pipino, el rey de los francos. Pipino aceptó la petición, y de hecho procedió al establecimiento de una alianza entre ambos, por medio de la cual obtuvo del papa que lo consagrara tanto a él como a sus hijos y esposa, sentando las bases más sólidas del derecho divino al trono que reclamarían después los reyes francos. Pipino rompió así su acuerdo con los longobardos y los combatió hasta debilitarlos sensiblemente y dejar a salvo Roma (Rendina, 2013: 179-184).

Maquiavelo da cuenta en ese mismo pasaje de esta relación entre el papa y Pipino, atribuyendo a un acuerdo entre éste y $\mathrm{Bi}$ zancio la concesión de un mayor margen de libertad a Venecia (Maquiavelo, 2009: 65). En realidad, Bizancio siguió tratando de someter a Venecia, al grado de que años después, ante las nuevas acometidas de los longobardos, el papa Adriano I le solicito a Carlomagno, el hijo de Pipino, que entrara en Italia nuevamente para hacerle efectiva la entrega de las ciudades del norte, lo que aprovecharon los venecianos para acudir ante Carlomagno en el 805 y ponerse a su resguardo, por lo que los bizantinos los acusaron de traición. A pesar de que tan solo siete años después, en el 812, Carlomagno restituyó Venecia a Bizancio, nunca se restablecieron del todo los vínculos de dependencia (Ravegnani, 2006: 47-102).

Venecia aprovechó durante todo este tiempo la debilidad de Bizancio para fortalecer sus estructuras de autogobierno. 
Desde principios del siglo VIII había logrado que el duque designado por Bizancio fuera elegido popularmente, lo cual constituyó un verdadero triunfo. No obstante, los duques así elegidos comenzaron a adquirir una gran autonomía frente a la asamblea popular, al grado de asimilarse a una figura monárquica. Tanto fue así, que el duque elegido en el 774, Maurizio Galbaio, tomo la decisión de asociar al ducado a su propio hijo, quien lo sucedió a su muerte sin que mediara la elección de la asamblea popular, una acción sin precedente. Esta decisión significaba en realidad la introducción del principio hereditario en una institución de gobierno en tránsito hacia la monarquía; un gobierno que hasta hacía no mucho tiempo tenía fuertes tintes democráticos, que había cedido ante lo que podría llamarse una monarquía electiva y que ahora apuntaba a convertirse en una monarquía hereditaria (Norwich, 1989; Ravegnani, 2013).

Poco después, en los primeros años del siglo IX, el dogo en turno tomó por esposa a una de las damas de la corte de Carlomagno, tratando de adoptar así la práctica que ya comenzaba a extenderse en las monarquías europeas, es decir, la asociación de sus casas reales mediante esta política de matrimonios, una práctica que tantos conflictos causó en los siglos posteriores.

La cuarta etapa de la historia de Venecia inicia en el siglo IX, cuando comienza a crecer y expandirse aceleradamente, convirtiéndose en una potencia comercial y naviera de enorme importancia, al grado de construir todo un Imperio marítimo que alcanza lugares distantes en el oriente.

Maquiavelo refiere cómo los venecianos por necesidad y vocación adquirieron una gran experiencia en los asuntos ma- rítimos, transportando tanto mercancías como personas, pues disponiendo de una gran flota naviera no faltaron quienes les solicitaron el transporte de sus bienes o sus ejércitos (Maquiavelo, 2009: 65).

En cierta medida ya en el siglo $X, y$ con toda plenitud en el siglo XI, Venecia se convirtió en toda una potencia económica. Siendo el transporte marítimo el principal medio de movilidad de media y larga distancia, los venecianos tuvieron el enorme acierto de construir a principios del siglo un arsenal naviero que se fue desarrollando hasta convertirse en el mayor de Europa, al grado de que para principios del siglo XV, la ciudad disponía de 3000 buques comerciales y 300 de guerra (Diehl, 1961: 69).

Su crecimiento comercial les permitió convertirse en señores del Adriático, al que llamaban nuestro golfo, pues llegaron a controlar todo el tráfico comercial en esta zona, estableciendo colonias a todo lo largo de la costa dálmata, llegando incluso a Creta, Chipre y la misma Bizancio.

Su presencia y desarrollo en toda la zona de influencia del Imperio bizantino, permitió a que después de la cuarta cruzada y de su papel relevante en ella se le concediera un importante número de posesiones, por lo que desde entonces el dogo fue llamado señor de un cuarto y medio del Imperio romano, es decir, gobernante y titular de los derechos de poco más de una tercera parte de esos dominios (Ravegnani, 2006: 103-122).

Por otro lado, durante todo este periodo, Venecia logró tejer una estrategia internacional para lograr darse un mayor margen de autonomía frente a las grandes potencias de las que se encontraba rodeada, pues la circundaban el reino de los francos, el ducado de Milán, el papa y 
sus Estados, el Sacro Imperio y el Imperio bizantino. Su habilidad le permitió incluso fungir como mediadora y anfitriona de la paz que alcanzaron en 1171 el papa y Federico Barbarroja.

Adicionalmente, su participación fue determinante para que no sólo ella sino muchas otras ciudades del norte de Italia lograran en esta época un mayor margen de autonomía frente al Imperio. Así, desde el siglo X y hasta el siglo XIII, se dio un gran auge de los gobiernos comunales en la zona, los cuales tuvieron que agruparse en la Liga Lombarda en 1168, en la cual Venecia participaba, para luchar contra Barbarroja y hacer respetar su autonomía. La derrota de los ejércitos imperiales en la batalla de Legnano en 1176 determinó el desenlace a favor de la Liga y condujo a la paz de Constanza en 1183, que garantizó a sus integrantes los derechos de a) elegir a sus propias autoridades, b) gobernarse libremente y c) hacer sus propias leyes (Martines, 1979: 25).

De este modo, durante esta etapa también se desarrollan y llegan a su plena madurez las principales instituciones constitucionales de Venecia. De hecho, hay dos momentos cruciales en esta transformación y construcción: 1172, cuando se arranca la elección del dogo a la asamblea popular y se le entrega a un pequeño consejo de notables; y 1297 , cuando se decreta la Serrata del Consiglio, el Cierre del Consejo, que consistió en restringir significativamente el acceso popular al Consejo Mayor. De este modo, por su relevancia para los propósitos de este escrito, es conveniente tratar por separado la creación o transformación de cada una de las instituciones de la constitución política veneciana (Pocock, 2002: 356-358; Lane, 1978: 108-120).
En primer lugar, comenzando con el dogo, debe notarse que fue durante este período que se transformó totalmente su función, pues sus tentaciones monárquicas se vieron seriamente coartadas en 1032 cuando se creó una ley para impedirle que nombrara un corregente o asociado, como habían venido haciendo varios de ellos desde fines del siglo VIII. Al mismo tiempo y con el mismo fin se crearon dos consejeros que debían acompañar su gestión para garantizar su rectitud (Ravegnani, 2013: 21; Norwich, 1989: 49-75).

Este fue solo el primer paso de una larga secuencia de medidas que se adoptaron para irle restando facultades y poder, pues las restricciones siguieron y se multiplicaron de manera aplastante. Luego de la imposición de dos consejeros en 1032, en 1178 se aumentó el número a seis, y se le prohibió dar audiencia o extender una carta oficial sin que estuvieran presentes al menos cuatro consejeros. En 1268 se le prohibió realizar operaciones comerciales, y más tarde, en 1347, se le prohibió tener propiedades fuera de Venecia, reduciendo así al mínimo su actividad económica. En 1275 se le prohibió a él y a sus hijos casarse con princesas extranjeras, y en 1343 se excluyó a sus hijos de la posibilidad de asumir cualquier magistratura. En 1400 se autorizo incluso a los abogados del municipio para que pudieran citarlo a juicio, y en 1523 se le prohibió poner su emblema fuera del palacio y salir al extranjero sin permiso.

Como puede verse, considerar al dogo de Venecia como la primera magistratura de la república no era sino un mero formulismo, pues estaba tan sujeto al Senado y al Consejo Mayor, que más parecía un secretario al servicio de una compleja maquinaria política. Como si fuera poco, en 
1339 se le había prohibido abdicar, para que no quedara duda de su incondicionalidad.

Con el mismo propósito, estaba establecido que el primer requisito para acceder al cargo era pertenecer a una familia inscrita en el Consejo Mayor. Además de ello, para mayores garantías, desde 1268, unos 30 años antes de la Serrata del Consiglio, se diseñó uno de los procedimientos electorales más complejos que haya creado el ingenio humano para la designación de un magistrado, en el cual intervenían sólo los miembros del Consejo Mayor que tuvieran más de 30 años de edad, lo que reducía ciertamente el universo electoral, pero no su tortuosidad (Coggins and Perali, 1998: 713-715; Lane, 1978: 131).

Como si no fueran suficientes precauciones contra del fortalecimiento del dogo, poco a poco se fue haciendo un requisito no escrito el que se eligiera a ancianos en los últimos años de su vida, al grado de que entre 1580 y 1720 su promedio de edad fue de 67 años, por lo que su mandato fue de aproximadamente cinco años. De tal manera, su carácter vitalicio quedaba así en otro mero formulismo (Burke, 1994: 112).

Como puede verse, el patriciado veneciano emprendió desde principios del siglo XI la construcción de todo un entramado legal e institucional para impedir que su dogo se convirtiera en señor de la república. Tantas precauciones no eran en vano, pues en los siglos XIII y XIV se registró toda una oleada de instauraciones de gobiernos señoriales en las ciudades del norte de Italia. La misma Venecia no estuvo exenta de este tipo de tentativas, pues en 1300, 1310 y 1355 enfrentó intentos de sublevación o golpes de estado para establecer este tipo de régimen (Tanzini,
2014: 163-186; Martines, 1979: 62-71; Beneyto, 1947: 33).

La segunda institución relevante de la estructura constitucional de Venecia era el llamado Colegio, que se comenzó a formar desde 1032 cuando se crearon los dos consejeros adjuntos al dogo, que aumentaron a seis en 1178 para formar lo que se llamó el Consejo Menor. Luego se le sumaron tres miembros de los Cuarenta, constituyendo en conjunto lo que se llamaba la Señoría, y finalmente se les agregaron 16 miembros más, los sabios, que en conjunto componían este órgano, que funcionaba como una especie de gabinete y estaba facultado para tomar algunas decisiones que requerían celeridad, sobre todo las relacionadas con los asuntos bélicos (Gilbert, 1980: 4; Gilbert, 1977b: 182-187).

En tercer lugar, hay dos instituciones relevantes que hay que considerar. Una de ellas es el Consejo de los Cuarenta, o Quarantia, creado en 1179 , dotado originalmente de facultades generales de gobierno y luego orientado especialmente a las funciones judiciales. Un órgano que por su número y su función llamaría notablemente la atención de Maquiavelo, como se verá después. Y la otra es el Consejo de los Diez, un órgano creado en 1310, luego del intento golpista de Bajamonte Tiepolo, cuya función era precisamente percibir y prevenir las inquietudes subversivas y las inconformidades potencialmente explosivas en la ciudad (Burkhardt, 1984: 37).

En cuarto lugar está el Senado, también llamado Consejo de los Rogados, o Pregadi, cuyo origen se remonta a 1172 cuando se creó una comisión de 11 patricios con la tarea de elegir al dogo, cuyo número aumentó a 40 en 1178 y a 60 en 1229, aunque en ciertos momentos llegó a con- 
tar con 150 o 200 miembros. Era llamado el Consejo de los Pregadi, los llamados, convocados o rogados, porque en su origen eran aquellos patricios miembros del Consejo Mayor que el dogo llamaba en primera instancia (Lane, 1978: 241).

En quinto lugar está el Consejo Mayor, el principal órgano legislativo y de representación política de la república de Venecia. Su origen se remonta al año de 1172 , cuando debido a una sublevación se decide quitar a la asamblea popular la facultad de nombrar al dogo y entregarla a un Consejo de notables compuesto por 480 personas, que serían elegidas por dos electores de cada uno de los seis barrios de la ciudad. Dado su carácter honorario, este Consejo comenzó a convertirse en el foro y receptáculo de las familias más acaudaladas y prestigiosas, lo que en una ciudad como Venecia, que ya era una potencia comercial y económica en esos años, significó convertirlo en el foro principal de la oligarquía. Eso explica que en 1297, consciente de su posición y su poder, la oligarquía haya decretado la Serrata del Consiglio, el Cierre del Consejo, que consistió en no permitir el acceso a éste más que a los individuos que pudieran acreditar algún antepasado que hubiera pertenecido a él, lo cual implicaba en el fondo favorecer a los miembros de las clases tradicionalmente mejor posicionadas.

Desde ese momento, y por medio de esta acción, la oligarquía veneciana tomó el control político de la ciudad, del que ya no se desprendería nunca. Desde entonces, sería en el seno de este Consejo donde se discutirían los grandes problemas del Estado y donde se decidirían las magistraturas más importantes.

Aunque en su origen estaba compuesto por 480 miembros, después descendió hasta casi doscientos. Paradójicamente, a partir de la Serrata de 1297, comenzó a crecer hasta que a principios del siglo XV llegara a albergar a 1500 o 2000 miembros, una cantidad de individuos que no tenía ningún otro órgano representativo de este tipo en el mundo. Siendo tan nuemeroso, el Consejo albergaba a una clase oligárquica bastante extendida, al grado de que su predominio se toleró de buen grado por el resto de la sociedad excluida, a quien además le garantizó por muchos años, siglos, paz y orden social; una república serenissima, por lo que su autoridad se hizo más legítima aún.

Maquiavelo no sentía especial animadversión por la oligarquía veneciana, por los patricios; no los consideraba un impedimento para la vida republicana. Planteaba ciertamente que toda república requería un importante grado de igualdad, pero en el caso de Venecia, no veía a los patricios tan acaudalados que impusieran una gran distancia con respecto al resto de la comunidad. Más aún, no creía que formaran la típica clase de gentilhombres, de nobles, típicos en muchas sociedades europeas, que se habían hecho rentistas y parasitarios. Los patricios venecianos debían su posición social a su intensa actividad económica y comercial, lo que Maquiavelo veía con simpatía (Maquiavelo, 2005: 172; Burke, 1994: 42-46).

Por otro lado, aunque se ha hablado muchas veces del celo y suspicacia con que los venecianos controlaban a su dogo, poco se dice acerca de que adoptaban esa misma actitud para con ellos mismos. Los patricios venecianos asumían seriamente la convicción de que uno de sus compromisos ineludibles era servir al Estado, pues de ello dependía su fortaleza y seguridad. Así, estaban conscientes de que debían acudir a su llamado en cuanto 
se les requiriera, que debían desempeñar las magistraturas que se les encomendaran, que no debían apelar o asociarse a otros gobiernos, y que debían evitar alinearse en facciones o rivalidades sociales.

Como puede verse, el orden de exposición de los órganos constitucionales de Venecia que se acaba de describir, no sigue el orden de importancia y jerarquía real que tenían a principios del siglo XV, en la época de Maquiavelo, más aún, de atender a ese criterio, bien podría seguirse un orden inverso. Sin embargo, se han expuesto así debido al orden de exposición de las ideas de Maquiavelo que se encuentra en el siguiente apartado.

La quinta etapa de la historia de Venecia es en alguna medida una continuación de la cuarta, ya que arranca a principios del siglo XV, cuando comienza a absorber una gran cantidad de ciudades y territorios vecinos en tierra firme, en el norte de la península italiana, por lo que esta etapa será mejor considerarla más ampliamente, para lo cual está dedicado el tercer apartado de este escrito (Braudel, 1986: 12-35).

\section{Constitución y estabilidad}

Ya en la época de Maquiavelo estaba bien difundida la reputación de Venecia como una república de vida longeva y una tranquilidad interior envidiable, los elementos esenciales en los que se basarían poco después Gasparo Contarini en su De magistratibus et republica venetorum (1543) y muchos otros escritores políticos para establecer lo que se conocería como el mito de Venecia (Pocock, 2002: 186; Finlay, 2000: 989).

Esta reputación no era en modo alguno gratuita, como tampoco el renombre que tenía como toda una potencia económica y política a nivel regional e internacional, que alcanzó su clímax en los primeros años del siglo XVI.

Como se ha dicho ya, Maquiavelo se refiere a Venecia por diversos motivos en la mayor parte de sus escritos, y en los Discursos se ocupa de ella con particular énfasis, sobre todo de su constitución política, haciendo tanto halagos como críticas a su diseño institucional, los cuales resultan del mayor interés para la teoría sobre las repúblicas.

Se puede comenzar por señalar la parte más visible del Estado, la figura que podría considerarse su timón, el dogo, la adaptación que los venecianos hicieron de la palabra duque, al que se refiere Maquiavelo en I,35.

En este capítulo, Maquiavelo trata una cuestión fundamental en el diseño institucional de una república: la magnitud de poder que debe conferirse a cada una de sus magistraturas. Aquí, Maquiavelo llama la atención sobre el peligro que representa dar autoridad suprema a un magistrado por un largo tiempo, por más de un año, incurriendo en el riesgo de que al prolongarse tanto el mandato, su desempeño dependa esencialmente de la buena o mala voluntad del individuo, lo que considera una vaguedad inadmisible para una república bien organizada. Maquiavelo advierte aquí de uno de los mayores riesgos que han enfrentado las repúblicas en todos los tiempos: cómo separar a los individuos de los cargos públicos más elevados en un tiempo prudente, cómo impedir que los salvadores de la república se conviertan en sus dictadores, en el sentido contemporáneo de este concepto. En El espíritu de las leyes, Montesquieu retomaría la adver- 
tencia para convertirla en una regla de diseño constitucional de primer orden En toda magistratura se ha de compensar la magnitud del poder con la brevedad de la duración (Maquiavelo, 2005: 124-5; Montesquieu, 1980:12).

En este mismo pasaje, Maquiavelo ejemplifica el riesgo con dos ejemplos, uno negativo y uno positivo. El negativo es el de los decenviros de Roma, a quienes se les entregó una autoridad muy importante, la de rehacer las leyes, una facultad que ejercieron sin restricción ni control alguno, anulando a los cónsules y tribunos, por lo que después no hubo autoridad alguna que pudiera oponérseles. El ejemplo positivo es precisamente el de los dogos venecianos, señalando el acierto de la república al someterlos a un control estricto para que no abusaran de su poder, ya que su carácter vitalicio podía conferirles una enorme autoridad. Al final de este pasaje también se deja asentada una idea que luego Lord Acton convertiría en una de las máximas de la política más repetidas. En palabras de Maquiavelo, una autoridad absoluta corrompe la materia en un tiempo brevísimo (Maquiavelo, 2005: 125; Giorgini, 2017: 70-72).

La advertencia no parecía inocua, pues aún hoy cualquier extranjero que se coloque en el centro de la plaza de San Marcos y observe la majestuosidad del Palacio de los Dogos, que se encuentra junto a la no menos fastuosa Catedral de San Marcos, podría pensar que tal edificio albergó a magistrados que en su momento debieron haber sido poderosísimos. No obstante, como se ha dicho ya, luego de su época de apogeo, en los siglos VII y VIII, la república se encargó de someterlos a tal restricción que para el siglo XVI apenas eran algo más que ministros subordinados.
En el Capítulo anterior de los Discursos, el I,34, Maquiavelo se había referido implícitamente a otras de las magistraturas importantes de la república. En ese Capítulo Maquiavelo habla de la importancia que tenían los dictadores romanos para el funcionamiento institucional de la república, ya que le daban una gran flexibilidad y adaptabilidad, porque eran nombrados por un período determinado muy breve y con el encargo de resolver un problema específico, lo que les permitía enfrentar ágilmente los cambios contingentes al interior y exterior del Estado.

Maquiavelo rebate en este pasaje a los críticos de esta institución, quienes planteaban que dio pábulo a la incursión y afianzamiento de los tiranos, a lo que él responde que si no hubieran usado esta vía, podían haber buscado cualquier otra. Maquiavelo insiste aquí en la importancia de que las repúblicas cuenten con un mecanismo expedito de decisión como éste; que les dé flexibilidad, que esté adecuadamente regulado y respaldado por la ley, y que esté sometido a los medios de vigilancia y control más convenientes. Si la ley no prevé recursos como éste, los gobernantes podrán verse tentados a buscar fuera de ella los medios de acción requeridos, con todos los inconvenientes que ello representa, porque si se instituye el uso de romper la ley para bien, bajo esta apariencia podrá romperse para mal (Maquiavelo, 2005: 122).

En este contexto es en el que Maquiavelo alude implícitamente al Colegio veneciano, una especie de gabinete que como ya se ha dicho se componía del dogo, sus seis consejeros, tres integrantes de la Quarantia y 16 sabios, quienes podían tomar decisiones relevantes sin necesidad de convocar al Senado o al Consejo Ma- 
yor, un recurso que Maquiavelo valora y reconoce como un acierto de la república.

En el Capítulo I,49, Maquiavelo vuelve a halagar algunas de las magistraturas de la república de Venecia, y lo hace en un contexto muy peculiar, pues en este Capítulo plantea que las ciudades que nacieron libres, sin estar bajo el dominio de un príncipe $u$ otro gobierno, construyeron instituciones apropiadas para la impartición de justicia, como Roma o Venecia; no así las ciudades que nacieron sujetas, como Florencia, su patria, que fallaron en esta tarea. Además de esta crítica a una institución gubernamental específica de su ciudad, lo más llamativo de este Capítulo es que Maquiavelo va más allá y reprueba de manera absoluta la organización política de Florencia, porque dice que durante doscientos años...no ha conocido gobierno por el cual pudiera ser considerada una república. Una crítica demoledora, dirigida no solo a la familia Medici que tomó el control del gobierno desde 1434, sino también a los regímenes políticos anteriores, que alcanzan hasta los gobiernos de los años veintes del siglo XIV, cuando la ciudad llamó a Gualtierio de Brienne, Duque de Atenas, para que la gobernara y acabara con los desórdenes previos (Maquiavelo, 2005: 155; Guicciardini, 2006: 111-123; Martines; 1979: 94-110).

En este mismo Capitulo, tratando el asunto específico de la impartición de la justicia, Maquiavelo reconoce el acierto de Venecia al entregar esta facultad en primera instancia a su Consejo de los Diez, pero sin cometer el error de Florencia, que se la entregó a los Ocho en primera y última instancia. Maquiavelo advierte que la razón de ello es que en una república los pocos tienden a favorecer a los pocos, es decir, que las magistraturas reducidas en número o aisladas de la participación popular tienden a favorecer a los nobles, a la oligarquía, o al menos a ser más susceptibles a su presión. Por tal motivo, Venecia tuvo el acierto, comenta Maquiavelo, de encomendar esta función en primera instancia a los Diez, pero con la posibilidad de recurrir a una instancia superior, al Consejo de los Cuarenta, la Quarantia, que a su vez podía recurrir al Senado, el Consejo de los Pregadi, mismo que podía recurrir incluso en última instancia al Consejo Mayor, lo cual blindaba el proceso judicial ante presiones específicas.

Como puede verse, en estos últimos Capítulos del Libro I, Maquiavelo alude a las principales magistraturas de la república de Venecia: el Dogo, el Colegio, los Diez, la Quarantia, el Senado y el Consejo Mayor, y lo hace de una manera halagadora, reconociendo el acierto de su creación y diseño. No obstante, en la primera parte de este mismo Libro, Maquiavelo también examina la constitución de esta república, pero poniendo su atención en un aspecto distinto, no en su diseño institucional, sino en su estructura social, en la manera en que los distintos sectores sociales intervienen en el proceso político y en los efectos que esto produce. No obstante, en esta sección pueden observarse una serie de paradojas, incongruencias y contradicciones que son dignas de examinarse con detalle.

Siguiendo su característico método dicotómico, Maquiavelo analiza en el Capítulo I,5 y 6 en qué sector social de la república debe radicar la garantía de la libertad, si en los nobles o en el pueblo, y aunque no especifica claramente qué debe entenderse con ello, podría deducirse que trata de definir si las mayores prerrogativas de gobierno deben reservarse a uno $u$ otro 
sector. Si puede interpretarse así, entonces abre nuevamente la discusión sobre si es mejor una república aristocrática o una popular, a pesar de que poco antes, en el Capítulo I.2, había establecido que la mejor opción era el establecimiento de un gobierno mixto (Carty, 2016: 124-128; Stacey, 2014: 194-195).

Para dilucidar ahora esta alternativa, pone como ejemplos tres casos relevantes: el de Roma, que entregaba al pueblo esa atribución, constituyendo así una república popular; y el de Esparta y Venecia, que la entregaban a los nobles, determinando una república aristocrática, lo cual no deja de generar confusión, porque en el mismo Capítulo I.2 había clasificado a Roma y Esparta en el mismo tipo, como gobiernos mixtos.

No obstante, aceptando la nueva formulación de estos modelos, Maquiavelo afronta el problema, el dilema, de decidir cuál de ellos es mejor. Para resolverlo, establece que si se atiende a los resultados, es mejor el modelo aristocrático, ya que las dos repúblicas que constituyen su ejemplo, Esparta y Venecia, tuvieron una vida más larga, es decir, que ahí la garantía de la libertad fue efectiva por un período más prolongado. No obstante, Maquiavelo continúa diciendo que si se atiende a la razón, debe elegirse a Roma, porque ahí se entregó esta atribución, la garantía de la libertad, al sector social que menos interés tiene de usurparla, de estropearla (Soriano, 2009: 187).

¿Pero porqué se produce esta incongruencia? ¿Acaso la conducta que se guía por la razón no debe conducir a los mejores resultados?

Esta paradoja no termina aquí, sino que se magnifica al observar la solución de Maquiavelo. Plantea que de acuerdo a la razón, la mejor opción es una república popular, pues considera que contrariamente a lo que piensan los defensores de las repúblicas aristocráticas, quien está más indicado para resguardar la libertad es la plebe, porque no pudiendo asumir el control del Estado, será la más celosa en impedir que alguien más lo haga. Así, en este terreno, Maquiavelo decide guiarse por la razón y no por los resultados.

Como puede verse, se produce así una de las más grandes paradojas del pensamiento de Maquiavelo, del autor que revolucionó el método del pensamiento político en El príncipe, cuando dijo en su singular Capítulo XV que sin importarle apartarse de los métodos seguidos por otros escritores, él se guiaría por la veritá effettuale de las cosas y no por su immaginazione, es decir, por la verdad efectiva y no por suposiciones. Sin embargo, al parecer, en este problema no se ajusta a este método, pues hace a un lado los resultados objetivos que le brinda la historia y elige la opción que de acuerdo a la razón debía ser la mejor.

La explicación de la razón de Maquiavelo para preferir una república democrática y no una aristocrática conduce a otra paradoja no menos significativa. $Y$ es que su justificación para elegir una república democrática es más negativa que positiva, es decir, opta por el pueblo debido a su incapacidad para usurpar el poder de la república. Siendo un republicano convencido, lo más pertinente sería que planteara el acceso al poder del Estado de manera que se garantizara llevar allí a los ciudadanos más virtuosos, no solo a los menos perjudiciales, lo cual reduce la acción política a una negatividad que no parece acorde con el conjunto de su pensamiento (Carrithers, 1991: 248-251; Bobbio, 1992: 64-70). 
Maquiavelo agrega otra razón para preferir a las repúblicas democráticas que ineludiblemente conduce a una paradoja más. Cuando analiza qué sector social es más proclive a suscitar tumultos señala a los nobles, quienes al menos comparativamente están más inclinados a ello que la plebe. Sin embargo, reconoce que en sus dos ejemplos de repúblicas aristocráticas, Esparta y Venecia, sus instituciones políticas contuvieron admirablemente los tumultos nobiliarios, lo cual se debió, en el caso de Venecia, más al azar que a la prudencia de sus legisladores, pues cuando los venecianos juzgaron que ya eran suficientes para integrar un orden público, decidieron impedir el acceso al gobierno a los individuos que se incorporaran posteriormente a la comunidad. Desde ese momento, reservaron sólo a los patricios esa atribución, por lo que los primeros no tenían muchos argumentos para inconformarse, pues era una realidad que de antemano tenían que aceptar al instalarse ahí. Además, siendo considerable el número de los patricios, los excluidos constituían una minoría.

Maquiavelo se refiere aquí implícitamente a la famosa Serrata del Consiglio de 1297, aunque lo hace forzando notablemente la circunstancia histórica. Como se ha visto ya, la decisión que tomó en ese entonces la república de Venecia, guiada evidentemente por la oligarquía, no fue producto del azar, sino una medida completamente deliberada para restringir el acceso popular al Consejo Mayor, es decir, una restricción que aplicaría no sólo a los individuos que se incorporaran posteriormente a la comunidad, sino a una buena parte de la sociedad veneciana existente en ese momento.
Además de que no fue precisamente el azar lo que llevó a los patricios a tomar esta decisión, tampoco podría decirse que fue la consideración de haber llegado a ser suficiente número para formar un orden público, o sea un Estado, como lo dice Maquiavelo, pues atendiendo al volumen de la población y al desarrollo histórico que se reseñó antes, Venecia tenía siglos de ser capaz de constituirse políticamente.

Al final de este Capítulo I.6, Maquiavelo introduce otro elemento a considerar que se convierte en una paradoja más. Si había comenzado el Capítulo I.5 con el examen de qué modelo de república garantizaba mejor la libertad, si la aristocrática o la democrática, concluye este Capítulo relativizando esa determinación, pues plantea que hay dos soluciones igualmente válidas: debe elegirse una república aristocrática, como Venecia o Esparta, si el fin es que se conserve y sea duradera, pues al no armar al pueblo para disponer de un contingente numeroso y confiable de hombres armados, no podrá tener aspiraciones sólidas de expansión; y debe elegirse una república democrática si lo que se quiere es que se expanda y se convierta en un gran Imperio, como Roma, que armó a su pueblo para disponer de un gran ejército, afrontando el inconveniente de los tumultos que ello causó y que al final acortó su vida.

Agrega además una afirmación de difícil integración con el cuerpo de estos dos Capítulos: para constituir una república muy duradera, el método es ordenarla interiormente como Esparta o como Venecia...si se pudiera mantener este equilibrio, se encontraría la verdadera vida política (Maquiavelo, 2005: 51). 
De manera que se encuentran aquí dos principios contrapuestos: la garantía de la libertad, que dijo en el Capítulo I.5 que estaba mejor garantizada en la república democrática, y la verdadera vida política, que dice se encuentra en las repúblicas aristocráticas. Y entonces cabe la pregunta ¿Cuál de estas dos expresiones debe interpretarse como el fundamento más sólido de las repúblicas?

Adicionalmente, Maquiavelo introduce aquí el problema del equilibrio internacional. Desde su punto de vista, hay que elegir una república aristocrática si el objetivo es la estabilidad y la longevidad, aliciente al cuál se suma el que sólo en ésta es donde se puede encontrar la verdadera vida política. Sin embargo, para que sea efectiva esa estabilidad y durabilidad, la república debe ser de un tamaño mediano; ni tan débil para ser fácilmente vencida, ni tan fuerte que pueda atemorizar a sus vecinos e inducirlos a atacarla preventivamente. Pero Maquiavelo dice que este equilibrio es algo muy difícil de lograr, más aún, dice que todo equilibrio es efímero, por lo que al no haberlo, dejan de existir las condiciones propicias para la paz, estabilidad y longevidad, y por lo tanto, las condiciones necesarias para la vida política; entonces, la naturaleza del escenario internacional es más propicia a la existencia de repúblicas democráticas en expansión. En este sentido, Maquiavelo concluye este asunto afirmando que a pesar de todo, es mejor y más honorable diseñar una república que cuando tenga la necesidad de expandirse pueda hacerlo, como Roma, una república democrática, es decir, es una cuestión de principios, de razón.

Maquiavelo busca explicar la caída de Venecia en la batalla de Agnadello de 1509 conjuntando estos elementos: como era una república aristocrática que por definición no armó a su pueblo, esto le impidió tener la base y la fuerza apropiada para la expansión que intentó en esa época, lo que explica su caída (Maquiavelo, 2000: 29). Sin embargo, habría que advertir que esta interpretación se enfrenta a fuertes objeciones históricas. En principio, Venecia se enfrentó sola a una de las mayores coaliciones que hasta ese momento se hubieran conjuntado en la época, es decir, no puede plantearse sencillamente que la razón de su derrota era un defecto interno de su ejército. En segundo término, el ejército contra el cuál se enfrentó estaba integrado de la misma manera que el de ella, es decir, compuesto de mercenarios.

Como puede observarse, en estos dos Capítulos Maquiavelo incurre en varias paradojas y contradicciones difíciles de conciliar En primer lugar ¿a quién debe confiarse la garantía de la libertad, a los nobles o al pueblo?; en segundo lugar ¿en el análisis político e histórico, debe atenderse a la razón o a los resultados?; en tercer lugar ¿debe elegirse una forma de gobierno con base en los menores inconvenientes que contrae o bien en consideración de sus bondades?; en cuarto lugar ¿qué sector social produce mayores desequilibrios en el Estado, los nobles o el pueblo; en quinto lugar ¿cuál debe ser el criterio determinante para elegir una forma de gobierno, la estabilidad y conservación interior o la expansión exterior?; finalmente, en sexto lugar ¿cuál es el principio básico de una república, la garantía de la libertad o la verdadera vida política? Como se ha dicho ya, en todas estas disyuntivas Maquiavelo ofrece argumentos y conclusiones contradictorias y ambivalentes, al grado de que cualquier conclusión resulta de uno u otro modo disputable. 


\section{Expansión y sometimiento}

Maquiavelo se refiere en El príncipe en tres ocasiones a Venecia, y todas ellas tienen que ver de uno $u$ otro modo con su expansión territorial y con la manera en que gobernaba sus dominios (Maquiavelo, 2010: 56-58, 136, 143).

En el Capítulo III, Maquiavelo plantea que los venecianos introdujeron por ambición en Italia a Luis XII de Francia con la intención de obtener la mitad de la Lombardía, a pesar de que poco después fueron despojados por él mismo de esas posesiones. No obstante, si se pone en perspectiva y se contextualiza esta alianza de Venecia con Luis XII, se verá que tiene una explicación y significación más amplia que la simple ambición de los venecianos, como dice Maquiavelo (Maquiavelo, 2010: 5658; 2002: 316).

El primer antecedente digno de considerar es la guerra de Ferrara de 1484. En esa ocasión Venecia entró en disputa con Ferrara por la posesión de las salinas ubicadas en la desembocadura del río Po, cuyo monopolio reclamaba Venecia y Ferrara quería disputar. Al recrudecerse las diferencias y comenzar la guerra, Venecia se encontró con que los Estados italianos más fuertes, como Milán, Florencia y Nápoles se pusieron del lado de Ferrara, e incluso el papa que en un principio la apoyaba, cambió de bando, con lo que Venecia se encontró sola contra todos ellos. Fue entonces que en busca de apoyo convocó a Carlos VIII de Francia para que entrara en Italia y reclamara el trono de Nápoles, al que hereditariamente tenía algún derecho, y para que también su primo, el Duque de Orleans, el futuro Luis XII, reclamara el ducado de Milán, al cual lo ligaban igualmente ciertos derechos hereditarios. No obstante la invitación, el rey francés no bajó a Italia, ocupado con la rebelión nobiliaria que entonces enfrentaba (Norwich, 1989: 359-366; Diehl, 1961: 159-172).

Diez años después, en 1494, no fue Venecia quien convocó a Carlos VIII para intervenir en Italia, sino Ludovico el Moro, el Duque de Milán, quien pretendía afianzar su propia posición mediante el apoyo francés. En esta ocasión Carlos sí aceptó la invitación del Duque, ante lo cual Venecia se mantuvo neutral en un principio, pero poco después aceptó entrar a una coalición de varios Estados italianos para expulsar a los franceses del suelo italiano (Pellegrini, 2009: 23-48).

Con estos antecedentes como telón, Maquiavelo se refiere específicamente al acuerdo que tuvieron en Blois en 1499 Francia y Venecia, por medio del cual se despojaría a Ludovico del Ducado y se repartirían su territorio, del cual le correspondería a Venecia Cremona y todo el territorio al sudeste del Adda, hasta su confluencia con el Po. Como se ha dicho ya, algunos años después, Luis arrebataría a los venecianos estos territorios en el marco de la ofensiva de la Liga de Cambrai que derrotó a Venecia en 1509.

Como puede verse, Venecia trató de apoderarse de una porción de la Lombardía en un momento en que los Estados italianos y los ultramontanos estaban en expansión; era una situación de desequilibrio y turbulencia política en la que la supervivencia parecía estar asociada al crecimiento y ampliación más que a la contención y estabilización, tal y como Maquiavelo había descrito el orden internacional el final del Capítulo I.6 de los Discursos. Es decir, que describir el hecho simplemente como producto de la ambi- 
ción de los venecianos, como lo hace Maquiavelo, probablemente no ayude a entender mucho la situación (Guicciardini, 2006: 406-468).

En el Capítulo XX Maquiavelo deja ver también su animadversión en contra de Venecia, pues la acusa de fomentar las sectas güelfa y gibelina en las ciudades que habían sometido...con el fin... de que no se unieran en su contra (Maquiavelo, 2010: 136; Gilbert, 1977a: 295-322).

Como se ha dicho antes, desde principios del siglo XV Venecia venía construyendo un vasto Imperio en terra ferma, incluso había dado ya unos pasos antes, pues desde 1339 había sometido a Treviso, y aunque la perdió en 1381, la recuperó nuevamente en 1387. Sin embargo, su más fuerte tendencia expansiva se dio a principios de este siglo, más específicamente a partir de 1404.

En ese momento, Venecia aprovechó la muerte del duque de Milán, Gian Galeazzo Visconti, acaecida en 1402, quien durante los 17 años que gobernó Milán pudo expandir y fortalecer su dominio al grado de convertirse en una de las principales amenazas al equilibrio regional, incluso tuvo la habilidad para arrancarle al emperador en 1397 la concesión de convertir a Milán en un ducado, convirtiéndose así él mismo en el primer duque de ese Estado.

Por tal razón, los Estados vecinos experimentaron un gran alivio cuando murió, lo cual Venecia aprovechó además para comenzar una expansión vertiginosa en terra ferma. Así, tomó Verona y Padua en 1405, Rovereto en 1416, Udine en 1420, Brescia en 1426, Bergamo en 1428, Ravena en 1441, Crema en 1454, Cervia en 1463, Cremona en 1499, y a la muerte del papa Alejandro VI, en 1502, tomó Faenza, Rimini y Forli, importantes ciudades de la Romaña pertenecientes a los Estados pontificios, mismas que muy poco antes había conquistado César Borgia, el hijo de Alejandro, con las cuales pensaba construir un dominio y patrimonio para esta familia (Law, 1992: 154-155; Chabod, 1990: 585-590).

A fines de 1503, poco después de que los venecianos tomaran estas ciudades, Maquiavelo fue enviado a Roma en misión diplomática, lo cual le permitía observar estos acontecimientos desde una posición privilegiada. Apreciaba que Venecia era ya una seria amenaza para los Estados pontificios y advertía que el papa se convertiría en capellán de los venecianos si se hacen más grandes de lo que son (Maquiavelo, 2002: 172).

El mismo papa Julio II, artífice e impulsor de la Liga de Cambrai, no sólo tenía reclamos territoriales que hacer a los venecianos, sino también eclesiásticos. Deseaba recobrar una serie de prerrogativas eclesiásticas que desde hacía siglos se habían apropiado los venecianos, como el nombramiento de obispos y las contribuciones del clero local. Luego de su derrota en 1509, el papa pudo recobrar muchas de éstas (Gilbert, 1977: 111-120).

Como puede verse, en su larga y consistente tendencia expansiva, Venecia se había apoderado de ciudades y territorios pertenecientes a otros Estados, por lo que se había atraído el odio de muchos. Incluso algunos Estados que no habían sido directamente afectados se llenaron de suspicacias y recelos, pues los territorios y ciudades tomadas por los venecianos funcionaban frecuentemente como buffer en la región. De este modo, todos tenían algo que cobrarles o imponerles, tanto los Estados italianos como las potencias ultramontanas con fuertes intereses en la 
región, lo cual constituyó el ánimo con el que se fraguó la Liga de Cambrai. (Finlay, 1999: 933-939; y Finlay, 2000: 990-992)

No obstante, a lo largo del siglo XV en que Venecia se convirtió en un Imperio dentro de Italia, se forjó un renombre de tolerancia y benignidad ante sus colonias. Sus mismos métodos de conquista diferían notablemente con respecto a los otros Estados, ya que buscaba siempre no tomar a saco las ciudades que deseaban conquistar, sino buscaba irlas cercando hasta que estas se entregaran voluntariamente a su dominio, lo que hacía una diferencia notable. Además, trataba siempre de respetar hasta donde le era posible sus leyes, costumbres e instituciones, haciendo del dominio colonial algo menos odioso (Law, 1992: 166-174; Diehl, 1961: 173-207; Cronin, 1972: 134-193).

Incluso los venecianos solían concebirse como los defensores y protectores de la libertad en sus territorios dominados, por lo que su misma expansión era presentada como una campaña de protección de esas mismas comunidades, planteando que al protegerlas procuraba tanto su libertad como la suya propia, pues aseguraba así mejor sus fronteras (Baron, 1966: 392-395; Bowd, 2000: 404-406).

Es cierto que muchas de las ciudades que conquistó Venecia tuvieron un pasado de discordias múltiples, incluidas las que se daban entre güelfos y gibelinos, como lo dice Maquiavelo, pero la opinión que él emite del dominio veneciano no coincide con su real sistema de conquista y control, el cual, como se ha visto, era digno de admiración. Incluso unas líneas más adelante, Maquiavelo vuelve a forzar su interpretación del dominio imperial de Venecia cuando dice que al ser vencida en 1509 por la Liga de Cambrai en Vailate, o Agnadelo, como se conoce más generalmente a esta batalla, una parte de las ciudades que perdió cobró audacia y les arrebataron todas sus anteriores conquistas (Maquiavelo, 2005: 137).

Como es bien sabido, a la larga, en 1516, Venecia recobró casi todas sus posesiones previas a 1509, por lo que queda la duda de si este pasaje de los Discursos es previo a 1516, o bien, si es posterior. En este último caso, cabe preguntarse si Maquiavelo no se enteró de ello, lo cual es poco factible, o si aún enterado, ya no quiso o tuvo el cuidado de hacer la puntualización. Más aún, Maquiavelo debió estar informado que desde 1512 varias de esas ciudades se rebelaron en contra del dominio francés y trataron de volver al dominio veneciano, incluso era ya muy sonado el saco de Brescia de 1512 y la masacre que implicó, el cual se produjo como respuesta de los franceses a la organización de una sublevación para tratar de sacudirse su dominio y volver al campo veneciano. Al parecer, Maquiavelo vuelve aquí a dejarse guiar por su animadversión contra los venecianos.

\section{Conclusiones}

Como ha podido verse, Maquiavelo estimaba muy poco a los venecianos. Es cierto que, como dice Gilbert, Ios conocía poco, al menos en el plano personal, pues nunca estuvo en Venecia sino hasta el final de su vida, en 1525, cuando ya había escrito sus obras capitales. Sin embrago, evidentemente no son las cuestiones personales las que provocaron el juicio negativo de Maquiavelo con respecto a los venecianos, sino su posición y acción política, su actuación como Estado, la cual sí generó muchas circunstancias que avivaron su antipatía. 
En primer lugar, Venecia era una república, una república que en los 100 años precedentes había venido construyendo un Imperio muy considerable en el norte de la península, desafiando con ello la hipótesis y el deseo de Maquiavelo de ver unificada a Italia de la mano de un príncipe, tal y como lo plantea en el Capítulo XXVI de El príncipe, en donde recuerda el fracaso de César Borgia al intentarlo, pero traslada sus expectativas a un Medici, a un príncipe surgido de ese linaje florentino.

Es cierto que Maquiavelo era un republicano convencido, de ánimo ferviente y entusiasta, sin embargo, como el gran observador político que era, reconocía que había ciertas empresas y tareas que eran mejor desempeñadas por una sola persona, por un príncipe, como en este caso, que se trataba de la unificación de Italia, cuyo desorden y corrupción requería la mano firme de un soberano de este tipo. Además, dado que de acuerdo a Maquiavelo es mucho más factible librarse del yugo de un señor que del de una república, una vez cumplida la tarea, probablemente Maquiavelo habría concebido la hipótesis de que los italianos podrían sacudirse más fácilmente el dominio de un príncipe que el más pesado y duradero de una república, un yugo al que no quería ver sometida ni a Florencia, su patria, y tal vez tampoco al resto de los italianos.

En segundo lugar, Maquiavelo sentía animadversión contra Venecia por puro patriotismo, porque era una seria competidora de Florencia en una gran cantidad de aspectos. Los venecianos eran una competencia temible en el comercio, la industria, la banca, el transporte; el tamaño de su sociedad era mayor y la belleza de la ciudad rivalizaba con la de Florencia y cualquier otra de Italia y Europa. Aun cuando los florentinos eran muy reconocidos por su lengua, por sus artes y por sus monumentos, los venecianos tenían también importantes logros en cada uno de estos campos. Al considerar todos estos aspectos, sería difícil hacer un balance resolutorio, pero atendiendo al terreno estrictamente político y a su peso internacional, muy probablemente los venecianos salían ganando.

Partiendo de esa comparación, tal vez Venecia podía considerarse una potencia superior a Florencia, por lo que su capacidad y posibilidad de unir a la península era mayor, lo que no podía sino desagradar al apasionado florentino que Maquiavelo llevaba dentro. Vemos competir así en este caso dos de los valores más importantes para Maquiavelo, el nacionalismo y el republicanismo, de donde sale vencedor el primero.

En tercer lugar, Venecia empañaba la visión que Maquiavelo quería proyectar de la antigüedad. Para él, casi todo lo que habían hecho los antiguos era glorioso, heroico, ejemplar, digno de emular por los modernos, por sus contemporáneos, a quienes frecuentemente reprochaba su conformidad, indolencia y corrupción. De ahí que cuando en los primeros capítulos de los Discursos comienza a ilustrar sus afirmaciones, salgan a relucir los ejemplos de repúblicas renombradas: Atenas, Esparta, Roma y...Venecia, un ejemplo contemporáneo de una república ejemplar en más de un sentido; por su apacibilidad, por su longevidad, por su riqueza, por su constitución. Y entonces esa imagen épica y gloriosa de los antiguos que le permitía a Maquiavelo denostar y espolear a los modernos se desteñía en cierta medida, pues parecía evidenciarse que entre los modernos, entre los mismos italianos, también había ejemplos a seguir. 
En cuarto lugar, Venecia también estropeaba la valoración que Maquiavelo hacía de las repúblicas, ya que prefería a las democráticas, como Roma, por sobre las aristocráticas, como ella. Sin embargo, cuando las comparó, la república de los venecianos parecía desempeñarse mejor en algunos aspectos, como la tranquilidad interior y la durabilidad, algo contrario a la razón. Así, los mejores resultados de las repúblicas aristocráticas, como Esparta y Venecia, con respecto a la democrática Roma, lo forzaba a brindar alguna explicación de su preferencia, la cual lo condujo a la incómoda deducción de que había incongruencia entre la razón y los resultados, una paradoja que no puede verse sino como una seria inconsistencia en el pensamiento analítico de Maquiavelo.

En quinto lugar, Maquiavelo desprecia a Venecia por su organización militar, porque es el ejemplo de todo lo negativo que en esta materia él considera que se debe hacer. Venecia era un Estado que no tenía ejército propio, que dependía de mercenarios, la mayor falla en la que podía incurrir un Estado, en opinión de Maquiavelo. Él tenía un gran interés en las cuestiones militares, tanto por inquietud intelectual como por experiencia laboral. Su lectura de los autores clásicos romanos lo había llevado a admirar su espíritu y organización militar, basada en un ejército propio y popular. Además, durante su gestión como segundo secretario de la república, empeñó todas sus fuerzas y ánimos en la creación de un ejército similar para Florencia. Ciertamente Venecia no era el único Estado italiano que incurría en esta terrible falla, Florencia había cometido el mismo error durante mucho tiempo, lo cual Maquiavelo criticó reiteradamente con la misma reprobación que había dirigido a aquélla.
En este sentido, Maquiavelo interpretó la derrota fulminante de Venecia en la batalla de Agnadello de 1509 como una consecuencia lógica de esa falla estructural, una derrota que por un lado satisfacía la animadversión que sentía por ella y al mismo tiempo comprobaba su hipótesis sobre la necesidad de apoyarse en un ejército propio. Sin embargo, lo que Maquiavelo no podía saber en ese entonces era que la Serenissima fue la que salió mejor librada de estas guerras y la que defendió mejor su independencia y autonomía en los años posteriores.

\section{Bibliografía}

Baron, H. (1955). The Anti-florentine Discourses of the Doge Tommaso Mocenigo (1422-1423). En Humanistic and Political Literature in Florence and Venice. Cambridge: Harvard University Press.

Baron, H. (1966). The Crisis of the Early Italian Renaissance. Princeton: Princeton University Press.

Beneyto Perez, J. (1947). Fortuna de Venecia. Historia de una fama política. Madrid: Revista de Occidente.

Bisticci, V. (1963). Renaissance Princes, Popes and Prelates. New York: Harper Torchbooks.

Bobbio, N. (1992). La teoría de las formas de gobierno en la historia del pensamiento político. México: FCE.

Bowd, S. D. (2000). The Republics of Ideas: Venice, Florence, and Defence of Liberty, 1525-1530. History, 85 (279), 404-427.

Braudel, F. (1986). II secondo Rinascimento. Due secoli e tre Italie. Torino: Giulio Einaudi.

Bruckner, G. (1983). Tales of Two Cities: Florence and Venice in the Renaissance. 
The American Historical Review, 88 (3), 599-616.

Burckhardt, J. (1984). La cultura del Renacimiento en Italia. México: Porrúa.

Burke, P. (1994). Venecia y Amsterdam. Barcelona: Gedisa.

Carrithers, D. W. (1991). Not so Virtuous: Montesquieu, Venice and the Theory of Aristocratic Republicanism. Journal of the History of ideas, 52 (2), 245-268.

Carty, Jarrett A. (2016). "Machiavelli's Art of Politics: A critique of Humanism and the Lessons of Rome". En Kellow, Geoffrey y Leddy, Neven (eds.) On Civic Republicanism. Toronto: Toronto University Press, pp. 119-135.

Chabod, F. (1990). Escritos sobre el Renacimiento. México: FCE.

Coggins, J. S. y Perali, C. F. (1998). 64\% Mojority Rule in Ducal Venice: Voting for the Doge. Public Choice, 97 (4), 709-723. Cronin, V. (1972). The Flowering of Renaissance. Suffolk: Collins/Fontana.

Davies, S. y Davis, J. L. (2007). Greeks, Venice, and Ottoman Empire. Hesperia Supplements, 40, 25-31.

Diehl, C. (1961). Una república de patricios: Venecia. Madrid: Espasa-Calpe.

Finlay, R. (1999). The Immortal Republic: The Myth of Venice during the Italian Wars. The Sixteenth Century Journal, 30 (4), 931-944.

Finlay, R. (2000). Fabius Maximus in Venice: Doge Andrea Gritti, the War of Cambrai, and the Rise of Habsburg Hegemony, 1509-1530. Renaissance Quarterly, 53 (4), 988-1031.

Gilbert, F. (1954). The Concept of Nationalism in Machiavelli's Prince". Studies in the Renaissance, 1, 38-48.

Gilbert, F. (1977a). Machiavelli e Venezia. En Machiavelli e il suo tempo. Bologna: ॥ Mulino.
Gilbert, F. (1977b). Choice and Commintment. Cambridge: Harvard University Press.

Gilbert, F. (1980). The Pope, his Banker and Venice. Cambridge: Harvard University Press.

Gilbert, F. (1984). Machiavelli and Guicciardini. Politics and History in Sixteenth Century Florence. New York: Norton.

Giorgini, Giovanni (2017). "Machiavelli on Good and Evil: The Problem of Dirty Hands Revisited" En Johnston, David, Urbianti, Nadia y Vergara, Camila (eds.). Machiavelli on Liberty and Conflict. Chicago: Chicago University Press, pp. 58-86.

Guicciardini, F. (1932). Dialogo e discorsi del reggimento di Firenze. Bari: Laterza. Guicciardini, F. (2006). Historia de Florencia 1378-1509. México: FCE.

Hale, J.R. (1998). La Europa del Renacimiento 1480-1520. México: Siglo XXI.

Hay, D. y Law J. (1989). Italy in the Age of Reinassance 1380-1530. London: Longman.

Lane, F. C. (1978). Storia di Venezia. Torino: Einaudi.

Law, J. E. (1992). The Venetian Mainland State in the Fifteenth Century. Transactions of the Royal Historical Society, 2, 153-174.

Maquiavelo, N. (2002). Antología. BarceIona: Península.

Maquiavelo, N. (2000). El arte de la guerra. Madrid: Tecnos.

Maquiavelo, N. (2005). Discursos sobre la primera década de Tito Livio. Madrid: Alianza.

Maquiavelo, N. (2009). Historia de Florencia. Madrid: Tecnos.

Maquiavelo, N. (2010). El príncipe. Madrid: Alianza.

Maquiavelo, N. (2013). Epistolario 15121527. México: FCE. 
Martines, L. (1979). Power and Immagination. City-states in Renaissance Italy. New York: Alfred A. Knoff.

Mattingly, G. (1965). Renaissance Diplomacy. London: Penguin.

Montesquieu, Ch. S. (1980). El espiritu de las leyes. México: Porrúa.

Norwich, J. J. (1989). A history of Venice. New York: Vintage.

Pellegrini, M. (2009). Le guerre d'Italia 1494-1530. Bologna: II Mulino.

Pocock, J. G. A. (2002). El momento maquiavélico. El pensamiento político florentino y la tradición republicana atlántica. Madrid: Tecnos.

Psarra, Sophia (2018). Venice Variations: Tracing the Architectural Imagination. London: UCL Press.

Ravegnani, G. (2006). Bisanzio e Venezia. Bologna: II Mulino.

Ravegnani, G. (2013). I/ doge di Venezia. Bologna: II Mulino.
Rendina, C. (2013). I papi. Da San Pietro a papa Francesco. Storia e segreti. Roma: Newton Compton

Rubinstein, N. (1968). Florentine Constitutionalism and Medici Ascendancy in the Fitteenth Century. En Rubinstein, N. (comp.). Florentine Studies. Politics and Society in Reinassance Florence. Evanston: Northwestern University Press,

Salvatorelli, L. (1955). Sommario della storia italiana. Dei teimpi preistorici ai nostri giorni. Torino: Einaudi.

Soriano González, María Luisa (2009) "De la República de Maquiavelo a la República de Giannotti" Revista Internacional de Pensamiento Político, Vol. 4.

Stacey, Peter (2014). "Definition, Division, and Difference in Machiavelli's Political Philosophy". Journal of the History of Ideas. Vol. 75, No. 2, pp. 189-212.

Tanzini, L. (2014). A consiglio. La vita política nell'talia dei comuni. Bari: Laterza. 